\title{
Electromagnetic Shielding Effectiveness of Mineral Doped Waste Paper Fiber
}

\begin{abstract}
A. ÇIFCI $^{a, *}$ AND A.İ. KAYA ${ }^{b}$
${ }^{a}$ Mehmet Akif Ersoy University, Department of Electrical-Electronics Engineering, 15030 Burdur, Turkey

${ }^{b}$ Mehmet Akif Ersoy University, Department of Design, 15100 Burdur, Turkey

Electronics devices that facilitate our daily life are rapidly reaching into almost every area of our lives nowadays. Wireless communication using electromagnetic waves is preferred rather than wired communication due to the physical hardship in communication of these devices with each other. Electromagnetic waves provide communication between transmitter and receiver and also reach to unintended targets except receiver. If electromagnetic wave reaches an electronics circuit, it will cause the formation of undesired parasitic currents and the destruction of electronic circuits defined as electromagnetic interference. If electromagnetic wave reaches the tissue environment, it will change the structure and arrangement of cells at the molecular level depending on the wave frequency and power. As a result of long term exposure, it may cause cancer and its derivatives in living organism due to changes in cell structure. As seen in the electromagnetic studies, it may cause irreversible damage to living organism exposed to electromagnetic waves. Therefore, the study carried out will have an effect especially protection of living species against the electromagnetic wavelength's harmful effects. In this study, it is aimed to be performed of the mineral doped waste paper-based board design which will absorb electromagnetic waves that imposed nowadays in any environment. Experimental results show that electromagnetic shielding effectiveness of waste paper fibers with mineral powders $\left(\mathrm{BaSO}_{4}, \mathrm{C}, \mathrm{Fe}_{2} \mathrm{O}_{3}\right)$ is acceptable levels.
\end{abstract}

DOI: 10.12693/APhysPolA.134.265

PACS/topics: composite material, electromagnetic shielding, mineral powders, waste paper fiber

\section{Introduction}

Electromagnetic waves are spread by many natural and man-made sources and play an important role in our lives. As a result of the technological advances, the use of electromagnetic waves is increasing day by day, and therefore in daily life, electromagnetic waves are exposed to the levels above those found in nature. In recent years, public awareness of the potential adverse effects of electromagnetic waves on human health has increased. Electronic and telecommunication networks, FM and TV transmitters, satellite communication systems, military air defense systems, radar systems, automobile ignition systems, household appliances, medical devices, mobile phones, base stations, computers and overhead power lines intentionally or unintentionally create electromagnetic fields. The use of these devices, which have entered every moment of our lives facilitates our life and increases the intensity of electromagnetic waves, or in other words, electromagnetic pollution in living spaces. Electromagnetic fields cause not only the sensitive electronic devices to stop functioning but also undesirable effects in the human body. Electromagnetic field shielding is required to prevent these negative effects [1-3].

There are many materials developed to reduce the harm to the human health of the electromagnetic field. Electromagnetic efficiency, environmentally friendly and eco-efficiency are important in the proper selection of

*corresponding author; e-mail: acifci@mehmetakif.edu.tr these materials. Composite materials are the most effective materials that can be used for reflecting and absorbing electromagnetic waves by means of minerals added to structures. Composite materials are used in a diverse range of applications in every area from critical areas such as the defence industry to our homes. Considering the use of paper in the world, waste paper is an essential material and can be a major environmental problem. There is a large number of papers published about electromagnetic shielding as well as different aspects of the problem were studied [4-8]. However, the number of papers related to the use of waste paper as electromagnetic shielding is quite small. Shibata et al. [9] made woodceramics from waste paper with phenol resin in a thermal vacuum furnace. Results show that the waste paper woodceramics have a magnetic shielding effectiveness of $30 \mathrm{~dB}$ at $100 \mathrm{MHz}$ and $37 \mathrm{~dB}$ at about $400 \mathrm{MHz}$. In this paper, the electromagnetic interference shielding effectiveness in the frequency range of $300-2400 \mathrm{MHz}$ was studied on samples of waste paper fibers mixed homogeneously with mineral powders $\left(\mathrm{BaSO}_{4}, \mathrm{C}, \mathrm{Fe}_{2} \mathrm{O}_{3}\right)$.

\section{Electromagnetic shielding}

Electromagnetic field shielding is an enclosure used to block electromagnetic fields. There are three types of electromagnetic shielding, namely reflection, absorption and multiple-reflection. The reflection is the primary mechanism of shielding. The shield must possess mobile charge carriers (electrons or holes) which interact with the electromagnetic fields. The second important mechanism in electromagnetic shielding is absorption. The 
shield should need presence of electric and/or magnetic dipoles which interact with the electromagnetic fields. The third mechanism of shielding is multiple-reflection which is facilitated by large interface area or surface area $[4,10,11]$. Shielding effectiveness (SE) is defined as the ratio of the field strengths before and after attenuation of electric and magnetic field. SE is expressed in decibels $(\mathrm{dB})$ and can be written as [12]:

$S E=20 \log \left(\frac{E_{b}}{E_{a}}\right)=20 \log \left(\frac{H_{b}}{H_{a}}\right)=10 \log \left(\frac{P_{b}}{P_{a}}\right)$,

where $E$ is electric field in $\mathrm{V} / \mathrm{m}, H$ is magnetic field in $\mathrm{A} / \mathrm{m}$, and $P$ is power in $\mathrm{W} / \mathrm{m}^{2}$. SE can be expressed mathematically as the sum of the reflection $R$, absorption $A$ and multiple-reflection $M$ [13]:

$$
S E=S E_{R}+S E_{A}+S E_{M} .
$$

Materials used in electromagnetic shielding can be classified as high performance, standard performance and poor performance materials. Materials made like steel, copper, stainless steel and completely metal coated materials are high performance materials which have 80 $120 \mathrm{~dB}$ shielding effectiveness. Conductive metal plates or metal-particle plastics with shielding effectiveness of 20-40 dB are standard performance materials. Metallized fabric structures, conductive paper materials (conductive polymers) are poor performance materials with shielding effectiveness of 15-30 dB. Shielding effectiveness depends on the electromagnetic properties of the material, the shape of the shielding-forming parts, the frequency of the electromagnetic wave, the distance of the shield from the source, the thickness of the shield and the shielding material $[14,15]$.

\section{Experimental procedure and analysis of results}

The properties of the substances used in the study are as follows:

Waste paper. Wood is the primary raw material for paper industry. Paper is suitable for recycling. Waste paper used in the study was obtained from a waste paper collection center.

Binding agent. Polyvinyl acetate (PVAc) which is a polymer based thermoplastic resin is used as binder and matrix material in the study. Solvents of the polyvinyl acetate binder were provided ready-to-use from an industrial facility.

Barite powder $\left(\mathrm{BaSO}_{4}\right)$. Barite is mainly used in petroleum industry and has a white, light blue, light yellow, light red and light green color. Its main property is its high specific gravity $\left(4.5 \mathrm{~g} / \mathrm{cm}^{3}\right)$. Barite has the ability to absorb X-rays [16]. The world's barite resources known are about 550 million tons.

Activated carbon $(C)$. It is an organic substance that has color and odor retention especially in melts. It is an extremely fine, black powder. It is obtained by applying approximately $1000^{\circ} \mathrm{C}$ heat and high pressure to organic materials such as wood, coal, coconut. It has a porous structure. Thus, the surface area increases. Approximately $1 \mathrm{~g}$ has a surface area between $200 \mathrm{~m}^{2}$ and $1500 \mathrm{~m}^{2}$.

Iron (III) oxide $\left(\mathrm{Fe}_{2} \mathrm{O}_{3}\right)$. It is formed by the reaction of iron with oxygen in the presence of water or air. It occurs as a result of iron or steel corrosion. Various forms of rust can be detected visually or by spectroscopy and can occur under different circumstances. It is used as pigment and abrasive.

Waste paper used in the present study was cut into clippings in a smaller size as pre-treatment. The clipping waste paper was kept in separate cups at $20^{\circ} \mathrm{C}$ in a solid concentration of $10 \%$. Following this process, called pulp, the waste paper fiber was fully opened and a homogeneous mixture was formed in the mixer. The pulp was then washed with fresh water and dewatered on a 100 mesh screen to remove excess water before the harmful biological activation started. Thus, the solid waste relative humidity was reduced from $100 \%$ to $60-70 \%$. Then the relative humidity of the fibers was reduced to $2-3 \%$ in the drying kiln. The fiber mix prepared in $2-3 \%$ moisture in board production was mixed at the values indicated in Table I. Table I also lists the materials and production conditions used in experimental board production.

TABLE I

Variables and values of the experimental boards

\begin{tabular}{l|c}
\hline \hline Variables on the experimental boards & Values \\
\hline board sizes $[\mathrm{mm}]$ & $260 \times 260 \times 10$ \\
density $\left[\mathrm{g} / \mathrm{cm}^{-3}\right.$ ] & $0.65 \pm 0.05$ \\
adhesive (urea-formaldehyde) ratio & $10 \%$ \\
hardener $\left(\mathrm{NH}_{4} \mathrm{Cl}\right)$ ratio & $1 \%$ \\
mineral $\left(\mathrm{Ba}_{2} \mathrm{SO}_{4} ; \mathrm{C} ; \mathrm{Fe}_{2} \mathrm{O}_{3}\right)$ ratio & $10-20 \%$ \\
hot press temperature $\left[{ }^{\circ} \mathrm{C}\right]$ & $150-155$ \\
pressing time $[\mathrm{min}]$ & 5 \\
press pressure $\left[\mathrm{N} / \mathrm{mm}^{2}\right]$ & $2-2.5$ \\
thickness $[\mathrm{mm}]$ & 10
\end{tabular}

The draft board was prepared in ways that sprawled out waste paper fibers to be homogeneous in the dimensions of $260 \times 260 \times 10 \mathrm{~mm}^{3}$ metal frame. The cold preliminary press was applied to the prepared draft board before entering the hot press. After this process, experimental boards with a density of $0.65 \mathrm{~g} / \mathrm{cm}^{-3}$ $\left( \pm 0.05 \mathrm{~g} / \mathrm{cm}^{-3}\right)$ and the dimensions of $260 \times 260 \times 10 \mathrm{~mm}^{3}$ were manufactured. Table II indicates the mixing ratios of the samples used for this study and the structure and shielding mechanism of samples used in the study are shown in Fig. 1.

When the electromagnetic shielding graphs (Fig. 2) of the composite boards obtained by adding 10 and 20 by weight percent of mineral substance to waste paper fibers are examined, for carbon-doped boards, the lowest shielding value was measured at $15.5 \mathrm{~dB}$ and the highest shielding value at $52 \mathrm{~dB}$. The electromagnetic shielding ability of $20 \%$ carbon-doped sample was observed to be $8-10 \mathrm{~dB}$ more effective at $900 \mathrm{MHz}$ to $2100 \mathrm{MHz}$ than $10 \%$ carbon- 


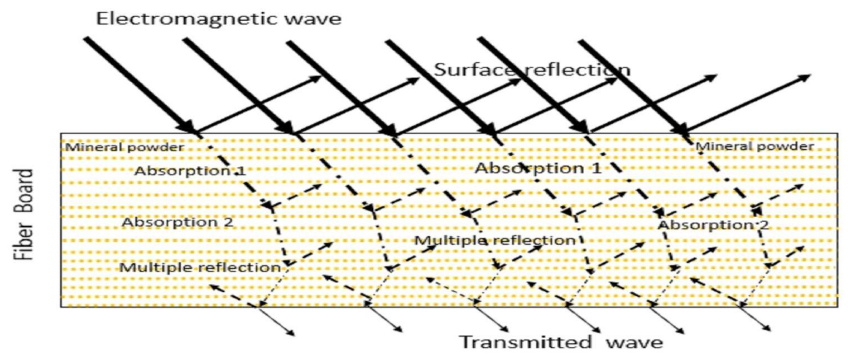

Fig. 1. The sample structure and shielding mechanism of fiber.

The mixing ratios of the samples

TABLE II

\begin{tabular}{l|c|c|c}
\hline \hline \multicolumn{1}{c|}{ Samples } & $\begin{array}{c}\text { Paper } \\
\text { pulp [\%] }\end{array}$ & $\begin{array}{c}\text { Mineral } \\
{[\%]}\end{array}$ & $\begin{array}{c}\text { Binder } \\
{[\%]}\end{array}$ \\
\hline barite+fiber (BaF1) & 80 & 10 & 10 \\
barite+fiber (BaF2) & 70 & 20 & 10 \\
carbon+fiber (CF1) & 80 & 10 & 10 \\
carbon+fiber (CF2) & 70 & 20 & 10 \\
iron (III) oxide+fiber (FeF1) & 80 & 10 & 10 \\
iron (III) oxide+fiber (FeF2) & 70 & 20 & 10
\end{tabular}

doped sample for carbon-doped samples (Fig. 2a). The lowest shielding value was measured at $15.5 \mathrm{~dB}$ and the highest shielding value at $52 \mathrm{~dB}$ for barite-doped boards (Fig. 2b). The shielding effectiveness of barite-doped boards is very close to each other. The lowest shielding value was measured at $16 \mathrm{~dB}$ and the highest shielding value was measured at $53 \mathrm{~dB}$ for iron (III) oxide-doped boards (Fig. 2c). When all samples are examined at the frequencies of $300 \mathrm{MHz}$ and $900 \mathrm{MHz}$, the samples were observed to have approximately at the same shielding value. $20 \%$ iron (III) oxide-doped board at $1800 \mathrm{MHz}$, $20 \%$ carbon-doped board at $2100 \mathrm{MHz}$ and $20 \%$ iron (III)
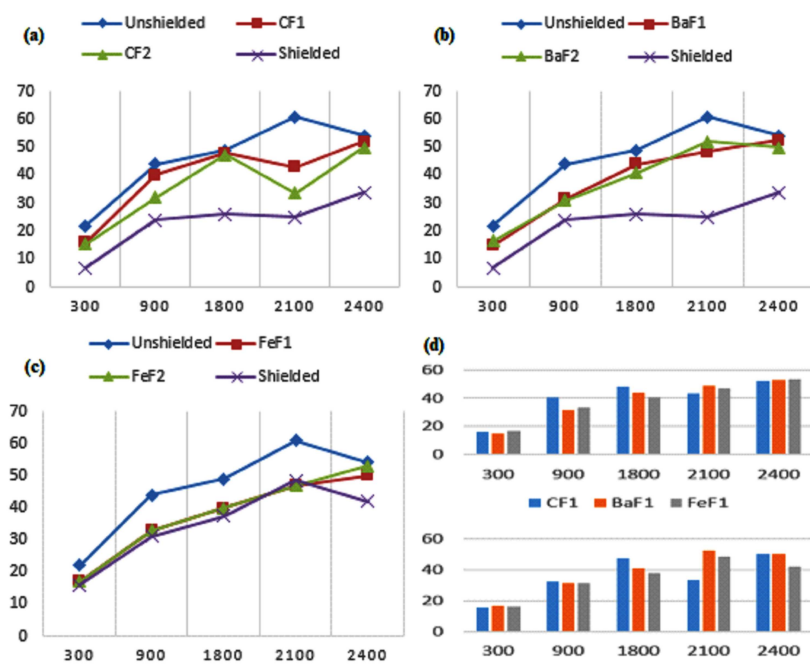

Fig. 2. Electromagnetic shielding effectiveness in dB: (a) carbon-doped boards, (b) barite-doped boards, (c) iron (III) oxide-doped boards, (d) comparison of boards. oxide-doped board at $2400 \mathrm{MHz}$ were showed superior shielding properties than other boards (Fig. 2d).

\section{Conclusion}

In this study, conductive mineral powders such as carbon, barite, and iron (III) oxide are added to waste paper fibers in two different ratios in order to provide electromagnetic shielding. Experimental results show that electromagnetic shielding effectiveness of waste paper fibers with mineral powders is of acceptable values. It has been determined that as the ratio of mineral powder at the measured frequencies increases, the shielding effectiveness also increases. At the same time, it has been observed that the shielding effectiveness decreases with increase of frequency. The main reason is that as shown in the experimental results, after $900 \mathrm{MHz}$ the permeability increased and the reflection decreased. At 1800 and $2100 \mathrm{MHz}$, this has been at the maximum level. Then, the permeability decreased and the shielding increased again at $2400 \mathrm{MHz}$. The results show that the shielding effectiveness of the board is directly related to the conductivity of that board. As a result, shielding effectiveness increases with increase of conductivity.

\section{References}

[1] X. Luo, D.D.L. Chung, Carbon 34, 1293 (1996).

[2] X. Luo, D.D.L. Chung, Composites Part B 30, 227 (1999).

[3] Z. Liu, G. Bai, Y. Huang, Y. Ma, F. Du, F. Li, T. Guo, Y. Chen, Carbon 45, 821 (2007).

[4] M.H. Al-Saleh, U. Sundararaj, Carbon 47, 1738 (2009).

[5] H.B. Zhang, Q. Yan, W.G. Zheng, Z.X. He, Z.Z. Yu, ACS Appl. Mater. Interfaces 3, 918 (2011).

[6] Z. Chen, C. Xu, C. Ma, W. Ren, H.M. Cheng, Adv. Mater. 25, 1296 (2013).

[7] B. Kanberoğlu, A.Ş. Demirkıran, Acta Phys. Pol. A 125, 642 (2014).

[8] S.C. Yener, O. Cerezci, Acta Phys. Pol. A 129, 635 (2016).

[9] K. Shibata, T. Okabe, K. Saito, T. Okayama, M. Shimada, A. Yamamura, R. Yamamoto, J. Porous Mater. 4, 269 (1997).

[10] D.D.L. Chung, Carbon 39, 279 (2001).

[11] C. Morari, I. Balan, J. Pintea, E. Chitanu, I. Iordache, Prgr. Electromagn. Res. PIER M 21, 93 (2011).

[12] N. Drake, Polymeric Material for Electrostatic Applications, Rapra Technology, Shropshire 1996, p. 106.

[13] P. Saini, M. Aror, in: New Polymers for Special Applications, Ed. A. De Souza Gomes, InTech, 2012, p. 71.

[14] E. Unal, A. Gokcen, Y. Kutlu, IEEE Microw. Mag. 7, 48 (2006).

[15] A.P. Singh, M. Mishra, S.K. Dhawan, in: Nanomagnetism, Ed. J.M. Gonzalez Estevez, One Central Press, UK 2015, p. 246.

[16] D.L. He, F.Q. Dong, Y.Q. Deng, Multipurpose Util. Miner. Resour. 2, 18 (2005). 